- Most European dental schools expect students to take tobacco histories from patients.

- A small number of schools need to update their approach to tobacco education in dentistry.

- There is still considerable variation between regions in Europe.

\title{
Policies and practices of European dental schools in relation to smoking; a ten-year follow-up
}

\author{
B. E. McCartan, ${ }^{1}$ and D. B. Shanley ${ }^{2}$
}

\author{
Objective To investigate the policies and practices of European dental \\ schools in relation to smoking as a ten-year follow-up. \\ Design A postal survey questionnaire. \\ Setting European dental schools in 2003.
}

Materials and methods Two hundred and one European dental schools were identified from the DentEd database. A postal questionnaire was sent to each with up to three follow-up letters to non-responders. Main outcome measures Results were tabulated and compared with the previous study (1993).

Results The effective response rate (allowing for errors in the database) was 149 of 199 schools (72\%). Eighty schools (59\%) had written tobacco policies, 132 (92\%) banned smoking in clinical areas, 127 (89\%) in nonclinical areas and 122 (85\%) in public access areas. One hundred and seven (76\%) expected students to take tobacco histories from all patients, while $79(69 \%)$ and $100(70 \%)$ respectively taught students anti-smoking advice and expected them to give such advice. The number of schools teaching the role of tobacco in oral cancer aetiology was 133 (93\%), in periodontal disease was 135 (94\%) and in osseointegrated implant failure was 127 (91\%). There was considerable regional variation between northern, southern and eastern Europe.

Direct comparison of the responses of the 78 schools that replied in both 1993 and 2003 showed some improvements in most of their policies and practices. However, there was some deterioration in the practices of southern European schools.

Conclusions While improvements were seen in the practices of most schools, comparison with recent US data suggests that European schools lag behind. However, self-selection of respondents may have introduced bias into the results.

\section{INTRODUCTION}

Worldwide mortality from tobacco-related diseases is estimated to reach in excess of 8,000,000 per annum by $2020 .{ }^{1}$ There is continuing evidence that dentists can be effective in delivering smoking cessation among their patients, ${ }^{2,3,4}$ although some recent work has cast doubt on these claims. ${ }^{5}$ However, there is

${ }^{1}$ Professor of Oral Medicine, School of Dental Science, Trinity College Dublin, ${ }^{2}$ Dean, Faculty of Health Sciences, Trinity College Dublin.

Correspondence to: Professor Bernard McCartan, Department of Oral Surgery, Oral Medicine and Oral Pathology, School of Dental Science, Trinity College Dublin.

Email: bernard.mccartan@dental.tcd.ie

\section{Refereed paper}

Received 30.09.03; Accepted 15.04.04

doi: $10.1038 /$ sj.bdj.4812196

๑ British Dental Journal 2005; 198: 423-425 very little evidence that dental schools are providing their students with the necessary tobacco counselling skills.

In 1995, we published the result of a postal survey carried out in 1993 of European dental schools to elicit their policies and practices in relation to smoking; the results were presented in the $B D J .^{6}$ That survey was based on the list of European dental schools maintained by the Association for Dental Education in Europe (ADEE). The essential findings were that while the majority of schools did include tobacco education in the curriculum, a disturbing number of responding schools did not expect students to engage with patients in relation to tobacco usage and cessation.

The original questionnaire was kept as brief as possible because of the potential language difficulties. Essentially the same questionnaire was used in the present study, with the addition of two new questions, one concerning smoking and periodontal disease and the other concerning smoking and osseointegrated implants.

At the time of our previous study, little was known about the policies and practices of dental schools, other than in North America. A US study published in 1990 had shown that only a minority of dental schools (19\%) expected students to provide tobacco counselling to patients. ${ }^{7}$ This figure had risen to $27 \%$ by $1994 .^{8}$ Since then, further information has emerged. In a study of US and Canadian dental schools, with a 98\% response rate, $75 \%$ included questions about tobacco use in health history forms and 44\% asked about the quantities of tobacco used. ${ }^{9}$ A 1998 questionnaire sent to 53 dental schools and 237 dental hygiene schools in the USA evoked responses of 93\% and 84\% respectively. All dental and dental hygiene schools required or encouraged students to enquire about tobacco usage, while 100\% of dental schools and $98 \%$ of dental hygiene schools required or encouraged students to advise patients to quit tobacco. ${ }^{10}$ A more recent US-based study of 54 dental schools found that 83\% provided instruction in tobacco prevention and $81 \%$ provided instruction in tobacco cessation. Ninety-six per cent expected students to take tobacco use histories. ${ }^{11}$ Another recent study looked at students' attitudes to tobacco cessation in a US based dental school. ${ }^{12}$ Two hundred and forty four students participated. Seventy-one per cent agreed that it is the dentist's responsibility to convince patients to quit and 74\% felt that dentists should set an example by not using tobacco. However, 39\% felt that their time would be better spent on other activities; these students were less likely to adopt smoking cessation procedures with their patients. The students' own current smoking practices were not reflected in their attitudes and practices in smoking cessation for their patients. 
The aim of the present study was to look for changes in the policies and practices of European dental schools in relation to tobacco over the ten-year period since 1993.

\section{MATERIALS AND METHODS}

The questionnaire was distributed to 205 institutions in 35 countries using a database obtained from the DentEd project. ${ }^{13}$ Up to three follow-up letters were sent to non-responders. Schools were invited to respond by post, by fax or by email. As before, the countries were divided into northern, southern and eastern (Table 1). As the three Baltic nations are now independent, it seemed logical to code them as northern along with the remaining Scandinavian/Baltic nations. During the taking of the survey, Yugoslavia became Serbia and Montenegro.

Not only were the previous and present studies based on different databases but also several schools had closed or amalgamated in the interim. As the samples in the studies were not strictly comparable, it was decided not to attempt statistical analysis of the responses. However, it was possible to undertake a detailed analysis of changes over the ten years in those schools that had responded to both surveys.

Statistical analysis was carried out using the EpiInfo statistical package (Centers for Disease Control, Atlanta, Georgia, USA).

\section{RESULTS}

Replies were received from 149 schools in 33 countries. Four replies indicated that the institution had closed or was not engaged in undergraduate training. Two schools misunderstood the request and distributed the questionnaire to students for completion. Two questionnaires were returned as undeliverable. The effective reply rate was, therefore, 143 of 199 schools (72\%). No replies were received from either Albania or Russia. The response rate varied across the regions (with the results of the 1993 study in brackets), northern 84\% (73\%), southern 55\% (58\%) and eastern 65\% (46\%).

The responses are shown in Table 2. We have highlighted some of these results below while attempting to parallel as far as possible the presentation of results in the previous study; in each case the percentage response is given in brackets along with the percentage response from the previous study. There were blanket smoking bans in clinical facilities, non-clinical teaching facilities and associated public access areas in 115 schools (81\% versus $61 \%$ ); 8 schools (6\% versus 6\%) had no such bans at all. As before, we examined the stated practices of schools to see if they were

\begin{tabular}{lll}
\multicolumn{2}{l}{ Table 1 Regional categorisation of schools replying to the questionnaire. } \\
\hline Northern & Southern & Eastern \\
\hline Austria & Greece & Belarus \\
Belgium & Italy & Bosnia Herzegovina \\
Denmark & Malta & Bulgaria \\
Estonia & Portugal & Croatia \\
Finland & Spain & Czech Republic \\
France & Turkey & Hungary \\
Germany & & Poland \\
Iceland & & Romania \\
Ireland & Slovakia \\
Latvia & Slovenia \\
Lithuania & Serbia and Montenegro \\
Norway & \\
Sweden & \\
Switzerland & \\
The Netherlands & \\
United Kingdom &
\end{tabular}

Table 2 Responses to questionnaires, percentages answering 'Yes', overall and by region. Results from the previous study are shown in brackets

\begin{tabular}{|c|c|c|c|c|c|c|c|c|}
\hline Question & $\begin{array}{l}\mathrm{N} \\
\text { No }\end{array}$ & $\begin{array}{l}\text { Jorth } \\
\text { Per cent }\end{array}$ & No & $\begin{array}{l}\text { South } \\
\text { Per cent }\end{array}$ & & $\begin{array}{l}\text { East } \\
\text { Per cent }\end{array}$ & No & $\begin{array}{l}\text { All } \\
\text { Per cent }\end{array}$ \\
\hline smoking policy? & 42 & $55(26)$ & 16 & $57(29)$ & 22 & $69(19)$ & 80 & $59(26)$ \\
\hline $\begin{array}{l}\text { Is smoking prohibited } \\
\text { in non-clinical } \\
\text { teaching facilities? }\end{array}$ & 71 & 89 (76) & 25 & 83 (67) & 31 & 94 (88) & 127 & $89(76)$ \\
\hline $\begin{array}{l}\text { Is smoking prohibited } \\
\text { in clinical facilities? }\end{array}$ & 73 & 91 (93) & 26 & 87 (95) & 33 & 100 (100) & 132 & 92 (94) \\
\hline $\begin{array}{l}\text { Is smoking prohibited } \\
\text { in public access areas } \\
\text { associated with } \\
\text { clinical facilities? }\end{array}$ & 68 & 85 (78) & 24 & $80(76)$ & 30 & 91 (63) & 122 & $85(75)$ \\
\hline $\begin{array}{l}\text { Do students take } \\
\text { tobacco usage } \\
\text { histories from } \\
\text { all patients? }\end{array}$ & 60 & 76 (49) & 24 & $86(71)$ & 23 & $70(75)$ & 107 & 76 (58) \\
\hline $\begin{array}{l}\text { Are students taught } \\
\text { anti-smoking advice } \\
\text { suitable for patients? }\end{array}$ & 52 & $67(42)$ & 20 & 69 (52) & 25 & 76 (75) & 97 & 69 (49) \\
\hline $\begin{array}{l}\text { Are students expected } \\
\text { to give anti-smoking } \\
\text { advice to patients? }\end{array}$ & 56 & 70 (43) & 18 & $60(52)$ & 26 & $79(69)$ & 100 & 70 (48) \\
\hline $\begin{array}{l}\text { Are students taught } \\
\text { the role of tobacco } \\
\text { in the aetiology of } \\
\text { oral cancer? }\end{array}$ & 74 & 93 (96) & 27 & 90 (100) & 32 & 97 (100) & 133 & 93 (97) \\
\hline $\begin{array}{l}\text { Are students taught } \\
\text { the role of tobacco } \\
\text { in the aetiology of } \\
\text { periodontal disease? }\end{array}$ & 75 & $94(-)$ & 27 & $90(-)$ & 33 & $100(-)$ & 135 & $94(-)$ \\
\hline $\begin{array}{l}\text { Are students taught } \\
\text { the role of tobacco } \\
\text { in the failure of } \\
\text { dental implants? }\end{array}$ & 71 & $92(-)$ & 26 & $90(-)$ & 30 & $91(-)$ & 127 & 91 ( - ) \\
\hline
\end{tabular}

internally consistent. Of the schools that expected students to counsel patients on smoking, 13 (13\% versus 32\%) did not expect them to take tobacco histories while 15 (15\% versus 18\%) of them did not teach suitable advice to impart. Seventy-four of the schools that expected students to counsel patients $(74 \%$ versus $60 \%$ ) not only taught both the role of tobacco in the aetiology of oral cancer and suitable advice to impart to patients, but also expected students to take tobacco histories.

Seventy-eight of the responding schools had responded to the previous study. These represented $75 \%$ of schools that had responded in 1993 and 55\% of the present respondents. They were distributed as follows: northern 52 (67\%), southern 7 (9\%), eastern 19 (24\%). This reflects the heavy bias towards responses from northern schools in the previous study. The numbers in the southern and eastern regions were too small to permit useful statistical analysis by region so the analysis was carried out on the entire group. The responses are shown in Table 3.

Within this subgroup of 78 schools responding to both questionnaires, there was almost no change in the proportion of schools teaching the role of tobacco in the aetiology of oral cancer $(74,95 \%$ in 2003 versus 75, 96\% in 1993) or in smoking bans in clinics $(72,92 \%$ versus $72,92 \%)$. All of the other questions showed an improvement over the ten years; smoking policies $(43,57 \%$ versus 20,26\%), smoking bans in nonclinical areas (69, 89\% versus 59, 77\%), smoking bans in public access areas associated with clinics (70, 90\% versus 55, 71\%), students expected to take histories (61, 80\% versus 43, 56\%), students taught appropriate smoking cessation advice for patients (54,71\% versus 40,51\%) and students expected to deliver smoking cessation advice (55, 


\begin{tabular}{|c|c|c|c|c|c|c|c|c|}
\hline \multirow[t]{2}{*}{ Question } & \multicolumn{2}{|c|}{ North } & \multicolumn{2}{|c|}{ South } & \multicolumn{2}{|c|}{ East } & \multicolumn{2}{|c|}{ All } \\
\hline & No & Per cent & No & Per cent & No & Per cent & No & Per cent \\
\hline Does your school have a written smoking policy? & $30(13)$ & $58(25)$ & $1(1)$ & $14(14)$ & $12(6)$ & $63(32)$ & $43(20)$ & $55(26)$ \\
\hline Is smoking prohibited in non-clinical teaching facilities? & $46(39)$ & $88(75)$ & $4(4)$ & $57(57)$ & $18(16)$ & $95(84)$ & $68(59)$ & $87(76)$ \\
\hline Is smoking prohibited in clinical facilities? & $48(47)$ & $92(90)$ & $4(6)$ & $57(86)$ & $19(19)$ & $100(100)$ & $71(72)$ & $91(92)$ \\
\hline Do students take tobacco usage histories from all patients? & $40(26)$ & $77(50)$ & $4(4)$ & $57(57)$ & $16(13)$ & $84(68)$ & $60(43)$ & $77(55)$ \\
\hline Are students taught anti-smoking advice suitable for patients? & $35(23)$ & $67(44)$ & $2(4)$ & $29(57)$ & $16(13)$ & $84(68)$ & $53(40)$ & $68(51)$ \\
\hline Are students expected to give anti-smoking advice to patients? & $35(24)$ & $67(44)$ & $3(3)$ & $43(43)$ & $16(12)$ & $84(63)$ & $54(39)$ & $69(50)$ \\
\hline Are students taught the role of tobacco in the aetiology of oral cancer? & $49(49)$ & $94(94)$ & $5(7)$ & $71(100)$ & $19(19)$ & $100(100)$ & $73(75)$ & $94(96)$ \\
\hline
\end{tabular}

$71 \%$ versus $39,50 \%)$. This last change was the only one to show statistically significance $(\mathrm{p}<0.05)$.

As stated earlier, analysis of the regional responses resulted in groups that were too small for statistical testing. However, a clear trend was observed in the data. The large improvements came in the northern and eastern schools. The southern schools showed no improvements in any category and, in the case of smoking bans in clinics, the teaching of suitable smoking cessation advice and the teaching of the role of tobacco in oral cancer aetiology, the southern schools showed quite large reductions in the proportions from 1993 to 2003.

\section{DISCUSSION}

Overall the results show considerable improvement in both the policies and practices of the schools surveyed (Table 2). The most notable improvements came in the northern European group. The proportion of schools with a written policy on smoking had more than doubled in the ten years. The proportion with clinical bans on smoking remained steady but there were clear increases in the proportion of bans applying to non-clinical facilities and public access areas. Some of this may reflect changes in legislation. Considerably more students are now expected to take tobacco histories from patients, the most notable improvement being in the northern schools, which previously had been well below the figures for southern and eastern schools. In northern and southern schools, there had been an improvement in the number of schools teaching anti-smoking advice while schools in all areas were now more likely to expect students to counsel patients against tobacco use. Schools in all areas seem to be making their students aware of the tobacco-related problems that can arise in periodontal disease and in osseointegrated implant therapy.

Where it was possible to make direct comparisons between the responses of individual schools between 1993 and 2003, there were marked improvements in the northern and eastern schools. However, the southern schools showed no improvement in most of the questions asked and, of particular concern to us, a deterioration in the responses to two of the questions. More than one quarter of these southern schools were not teaching the role of tobacco in the aetiology of oral cancer.

A potential source of bias was the variations in the regional response rates. The response rate from northern schools was rather greater than that from the other two regions. The data from northern schools is therefore likely to be more representative of the true state of these schools. In the other regions, there is a strong possibility that schools whose responses would have been 'unfavourable' were less likely to reply. In this regard, the low response rates of Spanish and Italian schools (38\% and 50\% respectively) may have resulted in a distortion of the results from the southern schools.

This stricture must apply particularly to the ten-year comparisons of individual schools. The analysis of northern schools is probably reasonably representative, given the similar numbers of responding schools to the two surveys (68 in 1993, 80 in 2003).

Comparisons can now be made with US practice. Although the two recent US papers cited above ${ }^{10,11}$ had different aims from our study, some of the results are comparable. In general, the European schools did not seem to be performing as well as their US counterparts. The proportion of European schools providing instruction in tobacco cessation was rather lower than the US figure (69\% versus $81 \%)$. The same is true of schools' expectations that students will take tobacco histories from all patients. The European figure (76\%) is rather lower than the US figure (96\%). It is clear that there is still considerable progress to be made in European schools, particularly in the southern European nations.

The European Working Group on Tobacco and Oral Health ${ }^{14}$ stated as one of its principal findings that current facts on tobacco and oral health and smoking counselling should be a fundamental part of the dental curriculum. It is unlikely that there will be any new EU legislation on dental undergraduate education. It will be necessary therefore to rely on national authorities to insist on a full place for tobacco education in the undergraduate curriculum. It will be easier to achieve this end if pan-European dental educational groups, such as DentEd and the ADEE, that might have the opportunity to take positive steps to bring about these changes, should do so as a matter of priority.

We would like to thank those schools and deans who cooperated with us in this study and the DentEd secretariat for allowing access to the database of European dental schools.

1. Murray C J, Lopez A D. Alternative projections of mortality and disability by cause 1990-2020. Lancet 1997; 349: 1498-1504.

2. Warnakulasuriya S. Effectiveness of tobacco counselling in the dental office. J Dent Educ 2002; 66: 1079-1087.

3. Tomar S L. Dentistry's role in tobacco control. J Am Dent Assoc 2001; 32 Suppl: 30S-35S.

4. Johnson N W. The role of the dental team in tobacco cessation. Eur J Dent Educ 2004 8 (Suppl 4): 18-24.

5. Rikard-Bell G, Donnelly N, Ward J. Preventive dentistry: what do Australian patients endorse and recall of smoking cessation advice by their dentists? Br Dent J 2003 194: 159-164.

6. McCartan B E, Shanley D B. Policies and practices of European dental schools in relation to smoking; the place of tobacco education in the undergraduate curriculum. BrDent J 1995; 179: 306-308

7. Fried J L, Rubenstein-DeVore L. Tobacco use cessation curricula in U.S. dental schools and dental hygiene programs. J Dent Educ 1990; 54: 730-735.

8. Grinstead C L, Dolan T A. Trends in U.S. dental schools' curriculum content in tobacco use cessation, 1989-93. J Dent Educ 1994; 58: 663-667.

9. Yellowitz J A, Goodman H S, Horowitz A M, Al-Tannir M A. Assessment of alcohol and tobacco use in dental schools' health history forms. J Dent Educ 1995; 59: 1091-1096.

10. Barker G J, Williams K B. Tobacco use cessation activities in U.S. dental and dental hygiene student clinics. J Dent Educ 1999; 63: 828-833.

11. Weaver R G, Whittaker L, Valachovic R W, Broom A. Tobacco control and prevention effort in dental education. J Dent Educ 2002; 66: 426-429.

12. Yip J K, Hay, J L, Ostroff J S, Stewart R K, Cruz C D. Dental students' attitudes toward smoking cessation guidelines. J Dent Educ 2000; 64: 641-650.

13. Shanley D B, Dowling P A, Claffey N, Nattestad A. European convergence towards higher standards in dental education: the DentEd Thematic Network Project. Med Educ 2002; 36: 186-192.

14. Johnson N W, Bain C A et al. Tobacco and oral disease. Br Dent J 2000; 189: 200-206. 